\title{
Load Shedding Apply Neural Network and Voltage Electrical Distance
}

\author{
Q. H. Anh ${ }^{1}$, \\ L.T. Nghia ${ }^{1}$, H.T.T. Hien ${ }^{1}$, \\ ${ }^{1}$ Faculty of Electrical and Electronics Engineering, \\ HCMC University of Technology and Education \\ Hochiminh City, Vietnam
}

\author{
P.T.T. Binh ${ }^{2}$ \\ ${ }^{2}$ Faculty of Electrical and Electronics Engineering, \\ HCMC University of Technology \\ Hochiminh city, Vietnam
}

\author{
Le Trong Nhan ${ }^{3}$, \\ ${ }^{3}$ LacHong University DongNai province, \\ Vietnam
}

\begin{abstract}
This paper proposed the method load shedding on the combination of Generalized Regression Neural Network and Voltage Electrical Distance to restore the system frequency to the value within the allowed range. The proposed load shedding method is based on the distance between the generator outage and the remaining nodes to ensure the frequency stability of the system. From there, the loads on the buses which are near the generator outage will be cut firstly, then the next loads until the system return to stable. The effectiveness of the proposed method are tested on the IEEE 39 Bus New England 10 Generators, which demonstrated the effective the proposed method.
\end{abstract}

Keywords: Load Shedding, Voltage Electrical Distance, Power Sensitivity, Neural Network, Frequency Control.

\section{INTRODUCTION}

Power system operation always is required to balance the active power and the reactive power between the source and the load. When the balance with the active power occurs, it'll give the serious for the frequency instability of the system. The methods such as reserve the hot standby power of the generation units in the system are only feasible and effective to achieve the above balance when the system is slightly overloaded (frequency of the system less a little). But in cases of serious power imbalance and lead to the blackout completely, the system need be used load shedding program to recovery the frequency.

Jianfeng and et al [1] have developed a method with risk indicators to determine the bus should be targeted for load shedding to maintain stable voltages. Buses with the highest voltages risk are prioritized for load shedding. This is estimated from the probability of the collapse of the voltage occurring. Risk indicators are the products of these probabilities and the effects of voltage collapse.

In [2], Hsu and et al presented a strategy of load shedding by performing artificial neural network (ANN) and transient stability analysis for an electrical system. To prepare the training data for ANN, transient stability analysis of a real power system has been made to address the minimized load with different operating scenarios. The Levenberg-Marquardt algorithm was combined with the back propagation algorithm for neural network training. By choosing the total generating capacity, total load demand and decay frequency are neural inputs of ANN, the output is the minimum number of load shedding that are identified to maintain the stability of the power system.

In this paper [3], a new approach based on hybrid Particle Swarm-Based-Simulated Annealing Optimization technique (PSO-B-SA) is proposed for solving under-voltage load shedding (UVLS) problem. Under voltage load shedding (UVLS) is one of the most important tools for avoiding voltage instability. In this paper, the UVLS problem is formulated based on the concept of the static voltage stability margin and its sensitivity at the maximum loading point or the collapse point. The voltage stability criterion is modeled directly into the load-shedding scheme. In any UVLS scheme finding the global point is very important for having cost effective economy. The proposed PSO-B-SA methodology is implemented in the under voltage load shedding scheme for IEEE 14 and 118 bus test systems. Simulation results show the efficacy and advantage of the proposed scheme.

A good load shedding program must shed the minimum number of loads as quickly as possible, it also meets all technical constraints to ensure a stable system. Conventional load shedding techniques are limited by load shedding overloading required and slow performance. Intelligent load shedding techniques mostly focus on investigating the timing of load shedding and the amount of load shedding. Studies on the location of load shedding are very limited.

This paper proposed the method of load shedding based on voltage electrical distance method. ANN neural networks are used to identify and classify load shedding control strategies based on the designed rules. The effectiveness of the proposed method has been tested on the IEEE 39 Bus New England.

\section{MATERIALS AND METHODS.}

A. Generalized regression neural network.

GRNN (Generalized Regression Neural Network) is a basic neural network, is a good tool for calculating approximations in the modeling toolbox. It predicts the output of a given input data. 


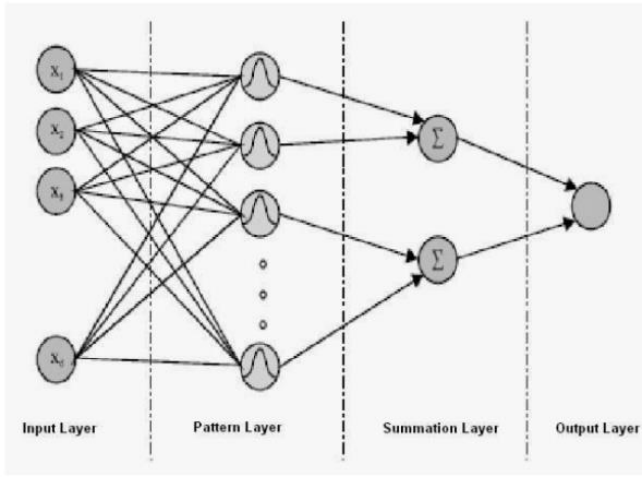

Fig. 1. Generalized regression neural network architecture [4].

Network structure include basic layer 4: input layer, pattern layer, summation layer and output layer. The main advantage of GRNN is to speed up the training process to help the network training faster [5].

\section{B. Voltage electrical distance}

Voltage electrical distance between the two nodes $\mathrm{i}$ and $\mathrm{j}$ is the following formula [6]:

$$
\begin{aligned}
& \mathrm{D}_{(\mathrm{i}, \mathrm{j})}=\mathrm{D}_{(\mathrm{j}, \mathrm{i})}=-\log \left(\alpha_{\mathrm{ij}} * \alpha_{j i}\right) \\
& \text { Where: } a_{i j}=\frac{\delta V_{i} / \delta Q_{j}}{\delta V_{j} / \delta Q_{j}}, a_{j i}=\frac{\delta V_{j} / \delta Q_{i}}{\delta V_{i} / \delta Q_{i}} \\
& \frac{\delta V_{i}}{\delta Q_{j}}, \frac{\delta V_{j}}{\delta Q_{j}}, \frac{\delta V_{j}}{\delta Q_{i}}, \frac{\delta V_{i}}{\delta Q_{i}} \text { are components extracted }
\end{aligned}
$$

from the inverse matrix of the Jacobian matrix.

The formula $\Delta \mathrm{V}_{\mathrm{i}}=\alpha_{\mathrm{ij}} * \Delta \mathrm{V}_{\mathrm{j}}[6]$ represents the voltage drop at node $\mathrm{i}$ when disturbance occurs at node $\mathrm{j}$. From formula (1), the distance near found, relative with $\mathrm{D}_{(\mathrm{i}, \mathrm{j})}$ small or $\alpha \mathrm{ij}$ as large. On the other hand, the larger the $\alpha_{\mathrm{ij}}$, the lower the voltage drop at node $\mathrm{i}$ when the disturbance at $\mathrm{j}$ as large. Thus, when the generator outage, the voltage fluctuation range near the fault node is large, resulting in the voltage drop at near nodes also increases, then load shedding will be at the nearest distance load buses or the largest voltage drop.

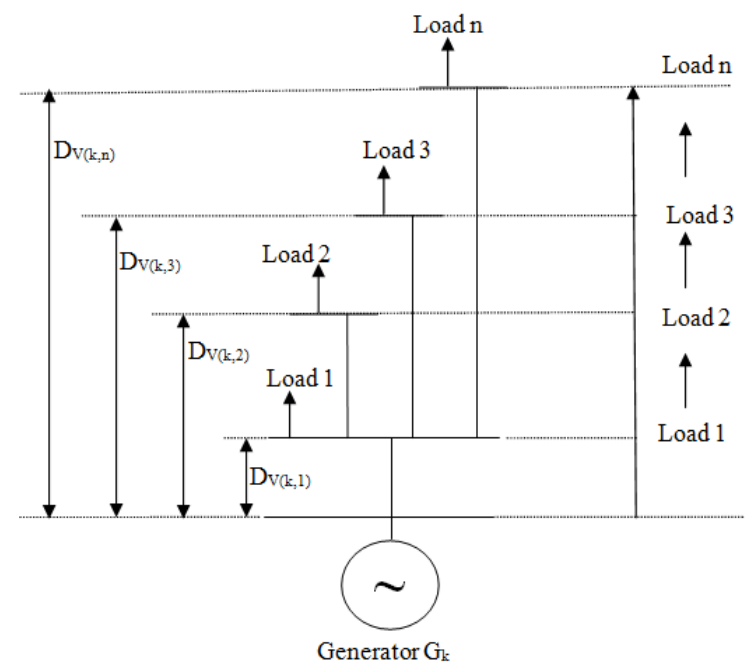

Fig. 2. The block diagram of the relationship between the generator $\mathrm{k}$ and the loads
With: $\mathrm{D}_{\mathrm{v}}(\mathrm{k}, 1)<\mathrm{D}_{\mathrm{v}}(\mathrm{k}, 2)<\mathrm{D}_{\mathrm{v}}(\mathrm{k}, 3)<\ldots<\mathrm{D}_{\mathrm{v}}(\mathrm{k}, \mathrm{n})$

Prioritized load shedding: Load $1 \rightarrow \operatorname{Load} 2 \rightarrow \operatorname{Load} 3 \rightarrow \ldots$ $\rightarrow$ Load $n$

\section{PROPOSED METHODS}

\section{A. Set up load shedding program}

Load shedding program are based on three main factors: the timing, the amount of load to be shed and the location of load shedding

The timing: The system data is sent to the control center for continuous measurement, when the system frequency is within the allowable range of $59.7 \mathrm{~Hz}<\mathrm{f}$, the load shedding program will start, the neuron function will be activated to identify the generator outage and the load shedding sequence. The operating time of the UFLS relay is about 0.1s [7] after the frequency falls below the allowable threshold and the process is carried out until the recovery frequency reaches the allowable value. In some emergency cases, (short circuit, loss of generator) this method cannot maintain system stability or restore the frequency with quite long time. Using smart computing technology, the proposed effective load shedding intervals require less than 500ms [8]. Here, the proposed load shedding period is $200 \mathrm{~ms}$. This time period includes: measurement of data acquisition, data transfer, data processing and tripping trip. However, to ensure safe margin in real time as well as allowable errors, a period of $100 \mathrm{~ms}$ [9] is added. So, in the simulation, here the proposed load shedding time is $300 \mathrm{~ms}$.

The amount of load to be shed: After obtaining the load shedding sequence list for each generator failure, use the offline PowerWorld simulation software to shed for each generator in trouble at different load levels. (including 21 load levels from $80 \%$ to $100 \%$ ). Dismissed until the frequency of the buses are within the allowable range of stopping, so that for each case the incident will have the number of load shedding corresponding to that case. The incident data collected would correspond to a number of load shedding from the trained neuron function.

Location of load shedding: Use voltage electrical distance for calculating distance between nodes. The load shedding position will be based on the distances from the generator outage (generator bus) to the remaining load buses to the load shedding order, or in other words the priority of the nodes closer to the generator will be first off, because these load nodes directly affect the generator is the most trouble.

The flowchart load shedding process is shown in Fig. 3.

\section{B. Application ANN to identify the failure.}

Due to the complexity of the power system, the abovementioned traditional methods take a lot of time to clear up, thus causing delays in decision making, The ANN method is used to solve difficult problems that traditional methods do not solve in terms of speed and performance.

However, ANN needs to be trained (learned) on the basis of initial data. Therefore, it is necessary to build the set to leran, including various outages. Data samples representing in each outage are the change in generator power $\Delta \mathrm{P}_{\mathrm{G}}$, the change of frequency in buses $\Delta \mathrm{f}_{\text {bus }}$, the voltage drop of buses $\Delta \mathrm{V}_{\text {bus }}$, the change of load $\Delta \mathrm{P}_{\text {load }}$ and the change of power distribution across the transmission lines $\Delta \mathrm{P}_{\text {branch. During the }}$ 
simulation, various load levels were considered to cover the operating modes.

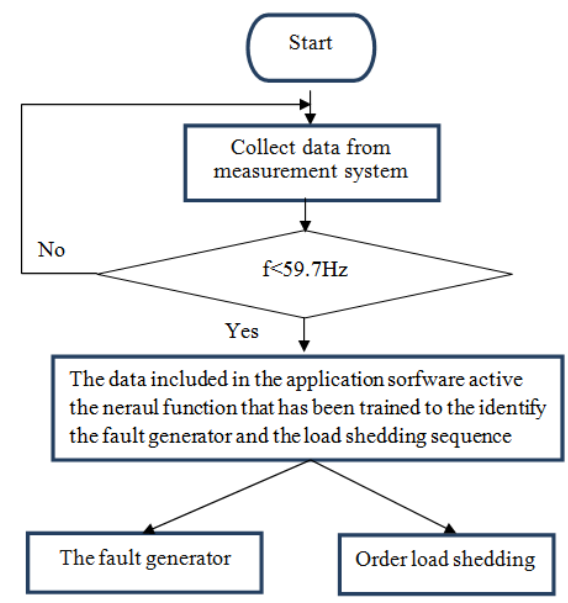

Fig. 3. Flowchart load shedding online

During the ANN model identification process, the creation database of the generator outage is considered the most important. Reliable databases not only determine the accuracy of the assessment, but also have a significant impact on the robustness of the model.

There are two elements that need to be clearly demonstrated during the simulation:

- The database must cover the operational status and must adequately represent the various incident scenarios.

- The generated database must ensure the objectivity of the parameters of the test power system.

The process of creating a database based on simulation PowerWorld and is done through the following 5 stages:

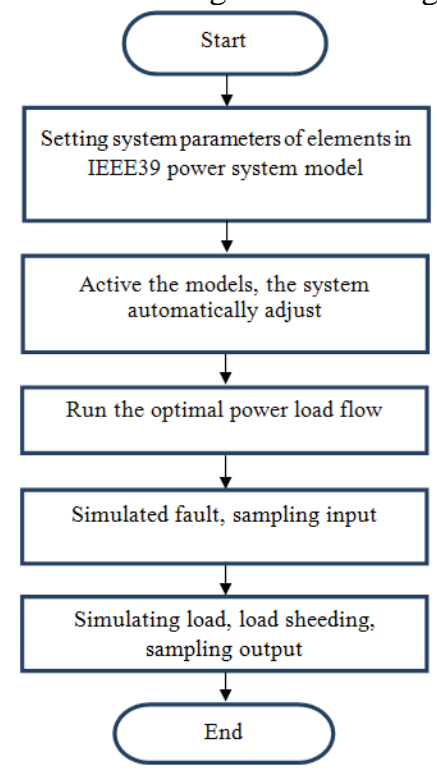

Fig. 4. Simulation steps for input, output sampling

Simulated fault, sample input is shown in Figure 5.

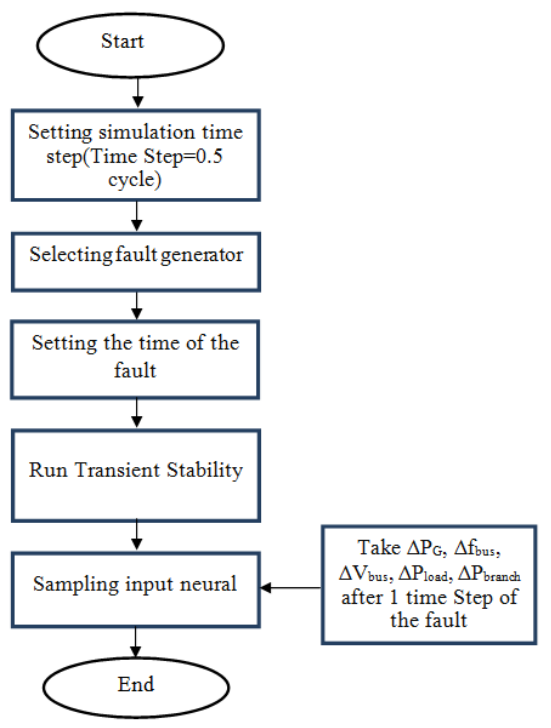

Fig. 5. Simulated fault, neural input sampling

Simulated fault, sample output is shown in Figure 6.

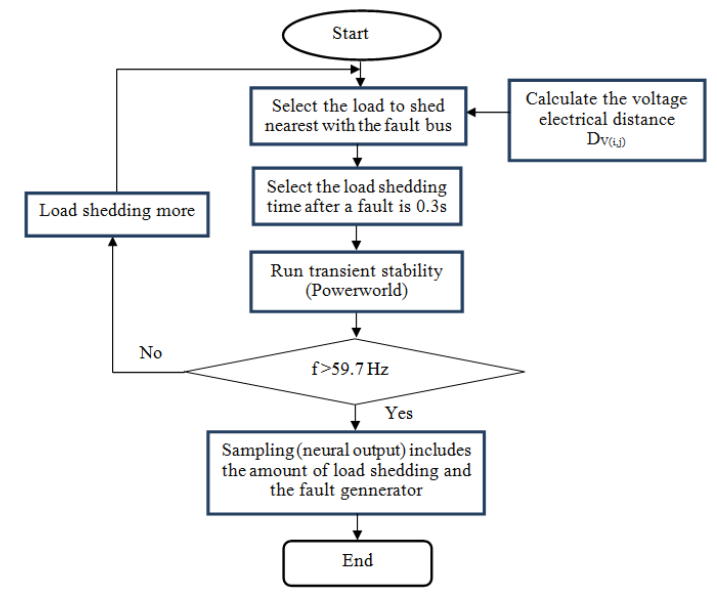

Fig. 6. Simulated load shedding, neural input sampling

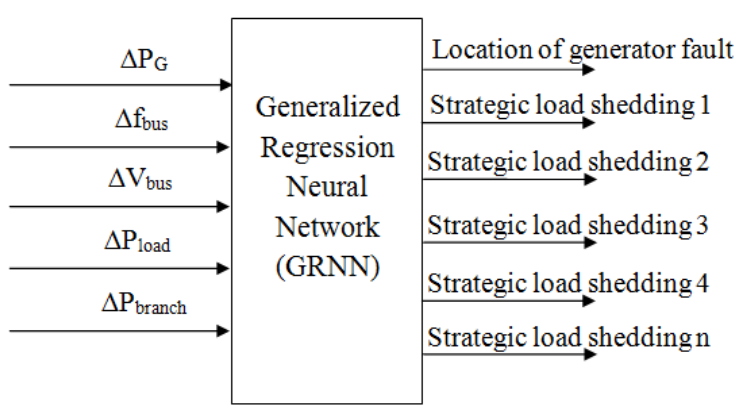

Fig. 7. Neural network training model with inputs and outputs

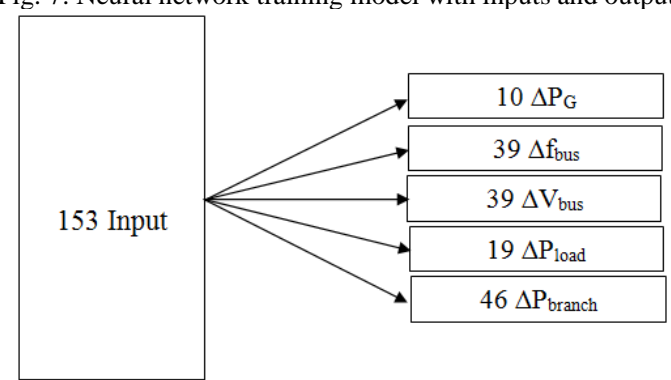

Fig. 8. Input data of the neural network 
IV. TESTING ON THE IEEE 39 BUS NEW ENGLAND

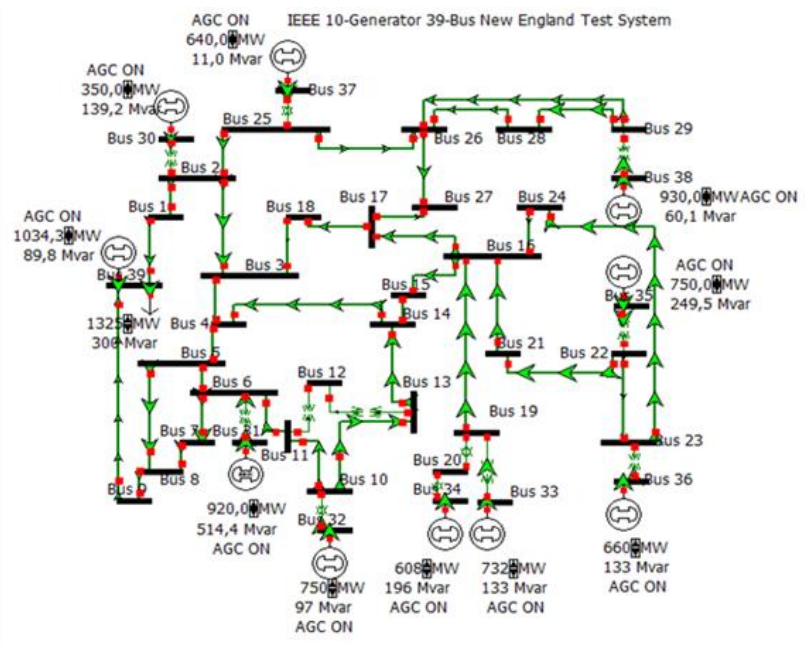

Fig. 9. The IEEE 39 bus New England

The proposed method is tested on The IEEE 39 bus New England, using Powerworld software to collect samples and Matlab software for neural network training.

\section{A. Process created a load shedding program}

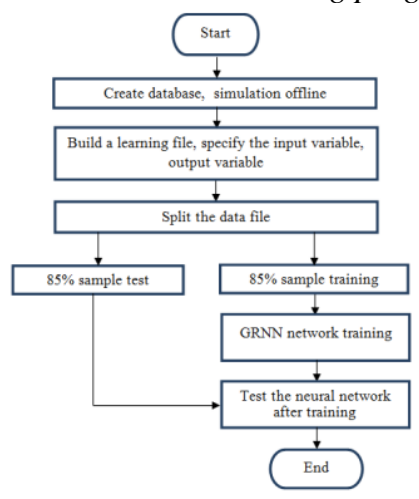

Fig. 10. Flowchart simulator sampling and neural network training

The process created a load shedding program use the neural network shown in Figure 10.

\section{B. Create fault database.}

Data is available when each generator outage occurs at different load levels $(80 \%$ to $100 \%)$. This process is done by off-line simulation using PowerWorld software.

Parameters representing in each case of generator faults are the change of generator power $\left(\Delta \mathrm{P}_{\mathrm{G}}\right)$, the change of frequency at the bus $\left(\Delta \mathrm{f}_{\mathrm{bu}} \mathrm{s}\right)$, the voltage drop at the bus $\left(\Delta \mathrm{V}_{\text {bus }}\right)$, the change in load capacity $\left(\Delta \mathrm{P}_{\text {load }}\right)$ and the change in power distribution across transmission lines $\left(\Delta \mathrm{P}_{\text {branch }}\right)$.

$C$. Calculate the phase electrical distance.

Voltage electrical distance is physical relationship between two buses in power system. Voltage electrical distance can be obtained by following step.

Step 1: Turning all PV generator buses into PQ load buses.

Step 2: From the matrix Jacobian J, have a matrix J4 from Powerworld, in which $\mathrm{J} 4=[\partial \mathrm{Q} / \partial \mathrm{V}]$

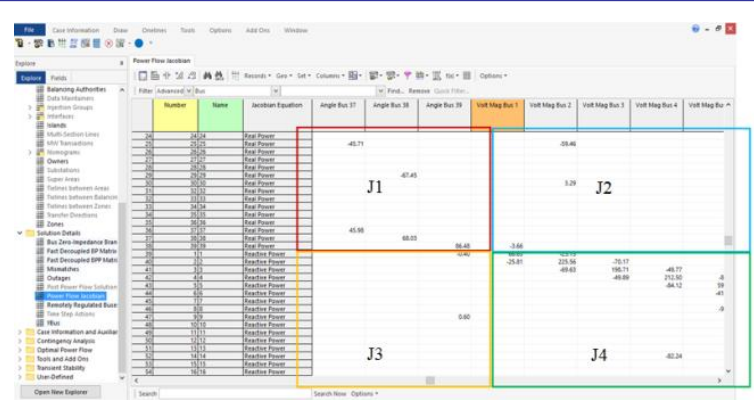

Fig. 11. The Jacobian matrix

Step 3: Inverse $\mathrm{J} 4$, call $\mathrm{B}=\mathrm{J} 4^{-1}$. Each element of matrix $\mathrm{B}$ is written:

$$
\mathrm{b}_{\mathrm{ij}}=\left[\frac{\partial \mathrm{V}_{\mathrm{i}}}{\partial \mathrm{Q}_{\mathrm{j}}}\right]
$$

Step 4: Take the $\alpha_{\mathrm{ij}}$ decrease matrix, between nodes $\mathrm{i}$ and

$\mathrm{j}$, as follows: $\quad \alpha_{i j}=\frac{b_{i j}}{b_{j j}}$

$$
\alpha_{j i}=\frac{b_{i j}}{b_{i i}}
$$

Step 5: Calculate the voltage electrical distance between nodes $\mathrm{i}$ and $\mathrm{j}$ calculated according to the formula (1):

$$
D_{i j}=D_{j i}=-\log \left(\alpha_{i j} x \alpha_{j i}\right)
$$

After completing step 5, we obtain table 1

TABLE 1. Table voltage electrical distance between the generator buses and the load buses.

\begin{tabular}{|l|l|l|l|l|l|l|l|l|l|}
\hline & Bus 30 & Bus 32 & Bus 33 & Bus 34 & Bus 35 & Bus 36 & Bus 37 & Bus 38 & Bus 39 \\
\hline Bus 3 & 0.2713 & 0.6145 & 0.5104 & 0.6583 & 0.4860 & 0.5908 & 0.3627 & 0.5117 & 0.4162 \\
\hline Bus 4 & 0.4117 & 0.4983 & 0.5665 & 0.7144 & 0.5421 & 0.6469 & 0.4949 & 0.6263 & 0.4479 \\
\hline Bus 7 & 0.5514 & 0.5471 & 0.7253 & 0.8732 & 0.7009 & 0.8057 & 0.6386 & 0.7783 & 0.4446 \\
\hline Bus 8 & 0.5339 & 0.5491 & 0.7153 & 0.8631 & 0.6909 & 0.7957 & 0.6221 & 0.7643 & 0.4053 \\
\hline Bus 12 & 0.7925 & 0.6192 & 0.9137 & 1.0615 & 0.8893 & 0.9940 & 0.8725 & 0.9968 & 0.7824 \\
\hline Bus 15 & 0.4517 & 0.6132 & 0.4053 & 0.5531 & 0.3809 & 0.4856 & 0.5106 & 0.5905 & 0.5427 \\
\hline Bus 16 & 0.4124 & 0.6393 & 0.3183 & 0.4662 & 0.2939 & 0.3987 & 0.4651 & 0.5323 & 0.5243 \\
\hline Bus 18 & 0.3432 & 0.6505 & 0.4561 & 0.6039 & 0.4317 & 0.5364 & 0.4074 & 0.4983 & 0.4790 \\
\hline Bus 20 & 0.7244 & 0.9513 & 0.2636 & 0.1542 & 0.6059 & 0.7107 & 0.7771 & 0.8443 & 0.8363 \\
\hline Bus 21 & 0.5188 & 0.7458 & 0.4248 & 0.5726 & 0.2317 & 0.3679 & 0.5716 & 0.6387 & 0.6308 \\
\hline Bus 23 & 0.5941 & 0.8210 & 0.5000 & 0.6479 & 0.2020 & 0.2170 & 0.6468 & 0.7140 & 0.7060 \\
\hline Bus 24 & 0.4657 & 0.6926 & 0.3716 & 0.5194 & 0.3064 & 0.3967 & 0.5184 & 0.5855 & 0.5776 \\
\hline Bus 25 & 0.2592 & 0.7422 & 0.6092 & 0.7571 & 0.5848 & 0.6896 & 0.1742 & 0.4549 & 0.4567 \\
\hline Bus 26 0.3793 & 0.7671 & 0.5769 & 0.7247 & 0.5525 & 0.6573 & 0.3553 & 0.2737 & 0.5449 \\
\hline Bus 27 & 0.3901 & 0.7334 & 0.5179 & 0.6658 & 0.4936 & 0.5983 & 0.3963 & 0.3713 & 0.5405 \\
\hline Bus 28 & 0.5605 & 0.9483 & 0.7581 & 0.9059 & 0.7337 & 0.8384 & 0.5365 & 0.1557 & 0.7261 \\
\hline Bus 29 & 0.5702 & 0.9580 & 0.7678 & 0.9156 & 0.7434 & 0.8482 & 0.5462 & 0.0828 & 0.7359 \\
\hline Bus 39 & 0.5220 & 0.8264 & 0.8426 & 0.9905 & 0.8182 & 0.9230 & 0.6309 & 0.8187 & 0.0000 \\
\hline
\end{tabular}

\begin{tabular}{|c|c|c|c|c|c|c|c|c|c|}
\hline & Bus 30 & Bus 32 & Bus 33 & Bus 34 & Bus 35 & Bus 36 & Bus 37 & Bus 38 & Bus 39 \\
\hline 1 & & 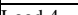 & & & & & & & \\
\hline 2 & Load 3 & Load 7 & Load 16 & Load 16 & Load 21 & Load 21 & Load 26 & Load 28 & Load 8 \\
\hline 3 & Load 18 & Load 8 & Load 24 & Load 24 & Load 16 & Load 24 & Load 3 & Load 26 & Load 3 \\
\hline 4 & Load 26 & Load 15 & Load 15 & Load 15 & Load 24 & Load 16 & Load 27 & Load 27 & Load 7 \\
\hline 5 & Load 27 & Load 3 & Load 21 & Load 21 & Load 15 & Load 15 & Load 18 & Load 25 & Load 4 \\
\hline 6 & Load 4 & Load 12 & Load 18 & Load 18 & Load 18 & Load 18 & Load 16 & Load 18 & Load 25 \\
\hline 7 & Load 16 & Load 16 & Load 23 & Load 23 & Load 3 & Load 3 & Load 4 & Load 3 & Load 18 \\
\hline 8 & Load 15 & Load 18 & Load 3 & Load 3 & Load 27 & Load 27 & Load 15 & Load 16 & Load 16 \\
\hline 9 & Load 24 & Load 24 & Load 27 & Load 27 & Load 4 & Load 4 & Load 24 & Load 24 & Load 27 \\
\hline 10 & Load 21 & Load 27 & Load 4 & Load 4 & Load 26 & Load 26 & Load 28 & Load 15 & Load 15 \\
\hline 11 & Load 39 & Load 25 & Load 26 & Load 26 & Load 25 & Load 25 & Load 29 & Load 4 & Load 26 \\
\hline 12 & Load 8 & Load 21 & Load 25 & Load 25 & Load 20 & Load 20 & Load 21 & Load 21 & Load 24 \\
\hline 13 & Load 7 & Load 26 & Load 8 & Load 8 & Load 8 & Load 8 & Load 8 & Load 23 & Load 21 \\
\hline 14 & Load 28 & Load 23 & Load 7 & Load 7 & Load 7 & Load 7 & Load 39 & Load 8 & Load 23 \\
\hline 15 & Load 29 & Load 39 & Load 28 & Load 28 & Load 28 & Load 28 & Load 7 & Load 7 & Load 28 \\
\hline 16 & Load 23 & Load 28 & Load 29 & Load 29 & Load 29 & Load 29 & Load 23 & Load 39 & Load 29 \\
\hline 17 & Load 20 & Load 20 & Load 39 & Load 39 & Load 39 & Load 39 & Load 20 & Load 20 & Load 12 \\
\hline 18 & Load 12 & Load 29 & Load 12 & Load 12 & Load 12 & Load 12 & Load 12 & Load 12 & Load 20 \\
\hline
\end{tabular}

From Table 1, we build the order of load shedding for each of the generator outage following in Table 2. 
Explanation: According to the suggested strategy table above, if there is a fault at generator 30, the load shedding order will be Load $25 \rightarrow$ Load $3 \rightarrow$ Load $18 \rightarrow \ldots$ until the system is stabilized again. Similarly, for the remaining generators.

D. Build a learning sample set, identify the input variable, output variable.

The number of sample data received via off-line simulation total plus 189 samples (including 21 load from $80 \%$ to $100 \%$, per each level have 9 case with 9 generators fault).

Building a learning template is a file under [samples $\mathrm{x}$ variables]. The samples are rows, and variables are columns.

Samples data in the learning template under the vector include the variables to the $\Delta \mathrm{P}_{\mathrm{G}}(10), \Delta \mathrm{f}_{\text {bus }}(39), \Delta \mathrm{V}_{\text {bus }}(39)$, $\Delta \mathrm{P}_{\text {load }}(19)$ và $\Delta \mathrm{P}_{\text {branch }}(46)$.

Total the into variables to $\mathrm{x}$ are $153=(10+39+39+19+46)$

$\mathrm{x}=\left[\Delta \mathrm{PG} \quad \Delta \mathrm{f}_{\text {bus }} \Delta \mathrm{V}_{\text {bus }} \Delta \mathrm{P}_{\text {load }} \Delta \mathrm{P}_{\text {branch }}\right]$

Output variables $\mathrm{y}$ is assigned as following: $\mathrm{y}=[\mathrm{y} 1 \mathrm{CL} 1$

CL2 CL3 CL4 ... CLn] $=13$

where: y1 is number of generator fault, CLn is strategic load shedding $\mathrm{n}$

Total results of the strategic load shedding on the table 3

TABLE 3. Load shedding strategy for each generator fault

\begin{tabular}{|l|l|}
\hline \multicolumn{1}{|c|}{ Strategic shedding } & \multicolumn{1}{c|}{ Load shedding } \\
\hline Strategic 1 (CL1) & L25 \\
\hline Strategic 2 (CL2) & L25, L3 \\
\hline Strategic 3 (CL3) & L4, L7 \\
\hline Strategic 4 (CL4) & L4, L7, L8 \\
\hline Strategic 5 (CL5) & L20 \\
\hline Strategic 6 (CL6) & L20, L16 \\
\hline Strategic 7 (CL7) & L23, L21, L16 \\
\hline Strategic 8 (CL8) & L23, L21, L24 \\
\hline Strategic 9 (CL9) & L25, L26, L3 \\
\hline Strategic 10 (CL10) & L25, L26, L3, L27 \\
\hline Strategic 11 (CL11) & L29, L28, 26, L27 \\
\hline Strategic 12 (CL12) & L39 \\
\hline
\end{tabular}

\section{E. Split the data file}

Data consists of 189 samples and split into two subsets: training data and test data. Training data covers all generator faults at various load levels as well as covers all strategies load shedding when the generator faults.

Training data is $85 \%$ of the samples (162 samples), test data is $15 \%$ of the samples ( 27 samples).

F. Neural network training and evaluation.

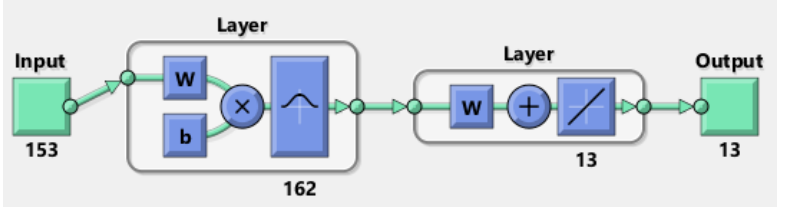

Fig. 12. Neural network training structure

After training, we tested to evaluate the accuracy after training through 27 samples (15\%) untrained, resulting in Table 4.
TABLE 4. Evaluate accuracy after neural training

\begin{tabular}{|c|c|c|c|c|c|}
\hline Order & $\begin{array}{c}\text { Output } \\
\text { variable }\end{array}$ & $\begin{array}{c}\text { Total test } \\
\text { sample }\end{array}$ & $\begin{array}{c}\text { Right } \\
\text { sample }\end{array}$ & $\begin{array}{c}\text { Wrong } \\
\text { sample }\end{array}$ & Right ratio \\
\hline 1 & y1 & 27 & 27 & 0 & $100 \%$ \\
\hline 2 & CL1 & 27 & 27 & 0 & $100 \%$ \\
\hline 3 & CL2 & 27 & 27 & 0 & $100 \%$ \\
\hline 4 & CL3 & 27 & 27 & 0 & $100 \%$ \\
\hline 5 & CL4 & 27 & 27 & 0 & $100 \%$ \\
\hline 6 & CL5 & 27 & 26 & 0 & $100 \%$ \\
\hline 7 & CL6 & 27 & 26 & 0 & $100 \%$ \\
\hline 8 & CL7 & 27 & 27 & 0 & $100 \%$ \\
\hline 9 & CL8 & 27 & 27 & 0 & $100 \%$ \\
\hline 10 & CL9 & 27 & 26 & 0 & $100 \%$ \\
\hline 11 & CL10 & 27 & 26 & 0 & $100 \%$ \\
\hline 12 & CL11 & 27 & 27 & 0 & $100 \%$ \\
\hline 13 & CL12 & 27 & 27 & 0 & $100 \%$ \\
\hline \multicolumn{7}{|c|}{ Average } \\
\hline
\end{tabular}

G. Test load shedding on the IEEE 39 bus New England by Powerwold.

Process simulation sampling with the IEEE 10 generators 39 bus are made as follows:

Assuming the generator outage is 34 , at load level $100 \%$, the frequency and deviation of the rotor angle become unstable.

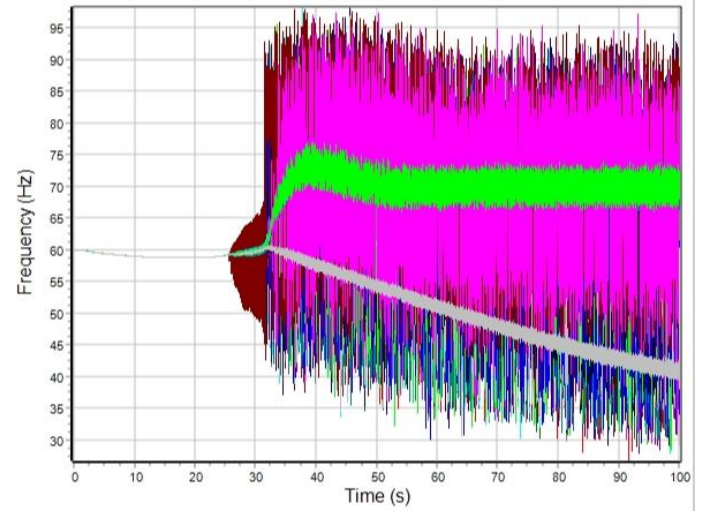

Fig. 13. Diagram of frequency of system at fault generator 34 load level $100 \%$ When implementing the proposed method, just load shedding the load on bus 20 , the frequency has stabilized.

\section{COMPARISON OF METHODOLOGY SUGGESTED WITH OTHER METHODS.}

A. Load shedding based on under frequency load shedding relays [10].

Load shedding based on under frequency load shedding relays is the most commonly used method, which is still being used in many parts of the world, including Vietnam. When the grid frequency falls below the permitted threshold, the relay will be load shedding, prevents the system frequency declines. Without this load shedding control, the greatest possible consequence is the blackout and the widespread outage.

For example, the FRCC load shedding program, has a load shedding plan under frequency load shedding shown in Table 5 .

\begin{tabular}{|c|c|c|c|c|}
\hline $\begin{array}{c}\text { Table 5. The FRCC load shedding program } \\
\text { Steps }\end{array}$ & $\begin{array}{c}\text { Frequency } \\
(\mathrm{Hz})\end{array}$ & $\begin{array}{c}\text { Time } \\
\text { delay (s) }\end{array}$ & $\begin{array}{c}\text { Amount of load } \\
(\% \text { of member } \\
\text { system) }\end{array}$ & $\begin{array}{c}\text { Cumulative } \\
\text { amount of } \\
\text { load }(\%)\end{array}$ \\
\hline A & 59.7 & 0.28 & 9 & 9 \\
\hline B & 59.4 & 0.28 & 7 & 16 \\
\hline C & 59.1 & 0.28 & 7 & 23 \\
\hline D & 58.8 & 0.28 & 6 & 29 \\
\hline E & 58.5 & 0.28 & 5 & 34 \\
\hline F & 58.2 & 0.28 & 7 & 41 \\
\hline L & 59.4 & 10 & 5 & 46 \\
\hline
\end{tabular}


In case of fault at generator 34 the load is $100 \%$, when the system frequency drops to $59.7 \mathrm{~Hz}$, it was load shedding $9 \%$ of total load. System frequency continues to fall, and when dropped to $59.4 \mathrm{~Hz}$, load shedding $7 \%$ of total load. The system frequency started to stabilize, the total load shedding was $16 \%(9 \%+7 \%)$.

B. Load shedding based on the AHP algorithm (Analytic Hierarchy Process) [11]

AHP is the approach to making decisions. This method presents balanced assessment options and criteria, and integrates them into a final decision. AHP is particularly suitable for cases involving analysis and quantification, make decisions when there are multiple options depending on the criteria with multiple interactions.

Strategic load shedding according to the AHP algorithm is shown in Table 6.

Table 6. The order of load shedding according to the AHP algorithm

\begin{tabular}{|c|c|}
\hline Order & Load \\
\hline 1 & L31 \\
\hline 2 & L12 \\
\hline 3 & L18 \\
\hline 4 & L26 \\
\hline 5 & L23 \\
\hline 6 & L25 \\
\hline 7 & L21 \\
\hline 8 & L28 \\
\hline 9 & L24 \\
\hline 10 & L3 \\
\hline 11 & L16 \\
\hline 12 & L15 \\
\hline 13 & L29 \\
\hline 14 & L27 \\
\hline 15 & L7 \\
\hline 16 & L20 \\
\hline 17 & L8 \\
\hline 18 & L4 \\
\hline 19 & L39 \\
\hline
\end{tabular}

In the case of generator 34 outage, the load is $100 \%$, load shedding according to AHP algorithm will be shed 31-12-1826-23-25, the system is stability.

C. Simulate and compare methods with each other.

\section{Frequency.}

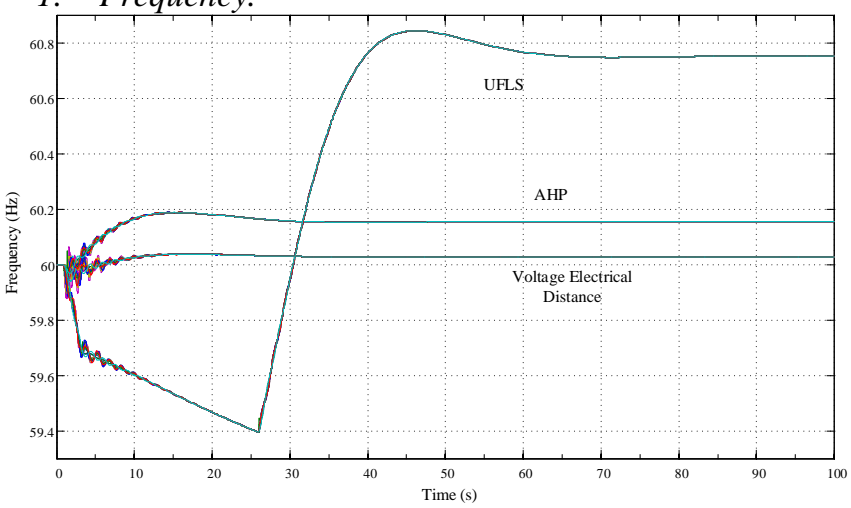

Fig. 14. Diagram of system frequency after generator 34 outage of all three methods of load shedding

Comparative results of the methods presented in Table 5.
Table 7. Comparative results of the methods

\begin{tabular}{|c|c|c|c|}
\hline Method & $\begin{array}{c}\text { Amount of load } \\
\text { shedding } \\
\text { (MW) }\end{array}$ & $\begin{array}{c}\text { Frequency } \\
\text { recovery time } \\
(\mathrm{s})\end{array}$ & $\begin{array}{c}\text { Frequency } \\
\text { stability } \\
(\mathrm{Hz})\end{array}$ \\
\hline UFLS relay & 975,52 & 65 & 60,75 \\
\hline AHP & 785,2 & 47 & 60,157 \\
\hline Proposed & 628 & 35 & 60,030 \\
\hline
\end{tabular}

In the case of generators 34 outage with a load level of $100 \%$, the proposed method has many advantages over the AHP method and the low frequency method, as follows:

The proposed load shedding method reduced the amount of load by $347.52 \mathrm{MW}(55.3 \%)$ compared to the traditional load shedding method and 157.2 MW (25\%) compared to the load shedding method based on the AHP algorithm.

The proposed load shedding method had a frequency recovery time of 30 seconds $(85.7 \%)$ compared to traditional load shedding and 12 seconds faster (34.3\%) than load shedding based on the AHP algorithm.

2. Voltage.

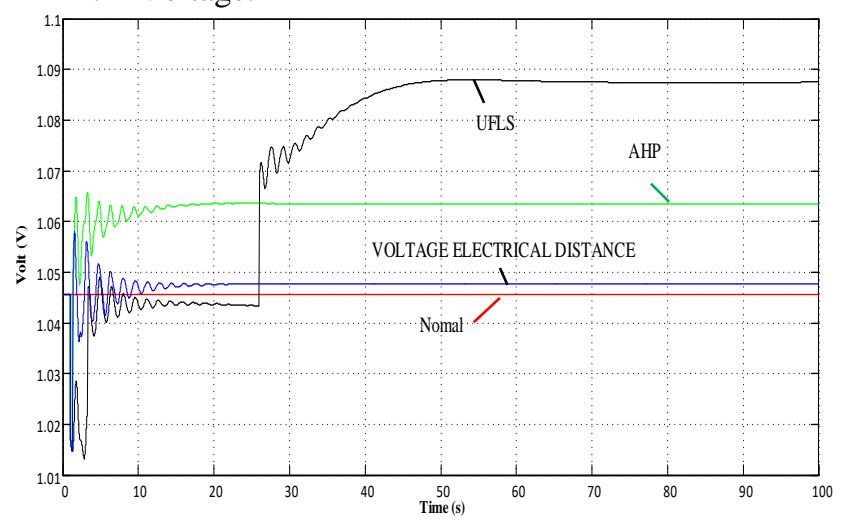

Fig. 14. Diagram of voltage after generator 34 outage of all three methods of load shedding

Table 8 . Comparison of recovery voltages at 19 bus loads when 34 generators were lost for all three methods

\begin{tabular}{|c|c|c|c|c|c|c|c|c|c|c|}
\hline \multirow[b]{2}{*}{ Bus } & \multirow[b]{2}{*}{$\begin{array}{l}\text { Normal } \\
\text { voltage } \\
\text { (pu) }\end{array}$} & \multicolumn{3}{|c|}{ ULFC } & \multicolumn{3}{|c|}{ AHP } & \multicolumn{3}{|c|}{ Proposed } \\
\hline & & $\begin{array}{c}\text { Recover } \\
\text { y } \\
\text { voltage } \\
\text { (pu) }\end{array}$ & $\begin{array}{l}\text { The } \\
\text { change in } \\
\text { voltage } \\
\text { variation } \\
(\%)\end{array}$ & $\begin{array}{l}\text { Recover } \\
\text { y time } \\
\text { (s) }\end{array}$ & $\begin{array}{c}\text { Recover } \\
\text { y } \\
\text { voltage } \\
\text { (pu) }\end{array}$ & $\begin{array}{l}\text { The } \\
\text { change in } \\
\text { voltage } \\
\text { variation } \\
(\%)\end{array}$ & $\begin{array}{l}\text { Recover } \\
\text { y time } \\
\text { (s) }\end{array}$ & $\begin{array}{c}\text { Recover } \\
\text { y } \\
\text { voltage } \\
\text { (pu) }\end{array}$ & $\begin{array}{l}\text { The } \\
\text { change in } \\
\text { voltage } \\
\text { variation } \\
(\%)\end{array}$ & $\begin{array}{l}\text { Recover } \\
\text { y time } \\
\text { (s) }\end{array}$ \\
\hline Bus 3 & 1.054 & 1.094 & $3.74 \%$ & 66 & 1.075 & $2.02 \%$ & 52 & 1.056 & $0.14 \%$ & 33 \\
\hline Bus 4 & 1.055 & 1.107 & $4.92 \%$ & 85 & 1.082 & $2.58 \%$ & 56 & 1.057 & $0.17 \%$ & 33 \\
\hline Bus 7 & 1.056 & 1.109 & $5.07 \%$ & 71 & 1.083 & $2.58 \%$ & 54 & 1.057 & $0.15 \%$ & 41 \\
\hline Bus 8 & 1.053 & 1.106 & $4.99 \%$ & 71 & 1.079 & $2.49 \%$ & 56 & 1.055 & $0.14 \%$ & 47 \\
\hline Bus 12 & 1.045 & 1.105 & $5.71 \%$ & 83 & 1.098 & $5.11 \%$ & 53 & 1.047 & $0.19 \%$ & 24 \\
\hline Bus 15 & 1.038 & 1.082 & $4.33 \%$ & 72 & 1.059 & $2.05 \%$ & 55 & 1.039 & $0.18 \%$ & 29 \\
\hline Bus 16 & 1.046 & 1.084 & $3.68 \%$ & 64 & 1.063 & $1.70 \%$ & 38 & 1.048 & $0.18 \%$ & 26 \\
\hline Bus 18 & 1.050 & 1.090 & $3.81 \%$ & 85 & 1.074 & $2.27 \%$ & 53 & 1.052 & $0.16 \%$ & 34 \\
\hline Bus 20 & 0.993 & 0.990 & $0.27 \%$ & 66 & 0.967 & $2.68 \%$ & 27 & 0.998 & $0.47 \%$ & 27 \\
\hline Bus 21 & 1.041 & 1.080 & $3.76 \%$ & 67 & 1.059 & $1.73 \%$ & 36 & 1.043 & $0.17 \%$ & 32 \\
\hline Bus 23 & 1.049 & 1.090 & $3.93 \%$ & 85 & 1.076 & $2.62 \%$ & 34 & 1.051 & $0.20 \%$ & 26 \\
\hline Bus 24 & 1.050 & 1.088 & $3.67 \%$ & 69 & 1.068 & $1.76 \%$ & 36 & 1.052 & $0.19 \%$ & 34 \\
\hline Bus 25 & 1.065 & 1.098 & $3.16 \%$ & 67 & 1.096 & $2.91 \%$ & 43 & 1.066 & $0.12 \%$ & 37 \\
\hline Bus 26 & 1.064 & 1.102 & $3.51 \%$ & 67 & 1.091 & $2.48 \%$ & 36 & 1.066 & $0.14 \%$ & 27 \\
\hline Bus 27 & 1.052 & 1.092 & $3.76 \%$ & 67 & 1.076 & $2.26 \%$ & 31 & 1.054 & $0.15 \%$ & 29 \\
\hline Bus 28 & 1.060 & 1.096 & $3.35 \%$ & 70 & 1.081 & $1.97 \%$ & 41 & 1.062 & $0.12 \%$ & 26 \\
\hline Bus 29 & 1.058 & 1.092 & $3.18 \%$ & 67 & 1.077 & $1.80 \%$ & 35 & 1.059 & $0.12 \%$ & 27 \\
\hline Bus 31 & 0.982 & 1.020 & $3.88 \%$ & 70 & 1.002 & $2.00 \%$ & 40 & 0.983 & $0.13 \%$ & 29 \\
\hline Bus 39 & 1.030 & 1.038 & $0.73 \%$ & 70 & 1.032 & $0.19 \%$ & 44 & 1.030 & $0.02 \%$ & 27 \\
\hline rage & 1.04 & 1.08 & $3.65 \%$ & 71.68 & 1.07 & $2.27 \%$ & 43.16 & 1.05 & $0.17 \%$ & 30.95 \\
\hline
\end{tabular}

In the case of generators 34 outage with a load level of $100 \%$, the proposed method has many advantages over the AHP method and the low frequency method, as follows:

The proposed load shedding method has a voltage recovery time of $131.6 \%$ compared to conventional method and $39.5 \%$ compared to the AHP algorithm. 
The proposed load shedding method has better recovering voltage values than traditional methods and AHP algorithm methods as follows: the change in voltage variation compared to the voltage before the fault of proposed load shedding method is $0.17 \%$, the traditional method is $3.65 \%$ and the AHP algorithm method is $2.27 \%$.

\section{CONCLUSION.}

The paper proposed a load shedding scheme with priority based on the voltage electrical distance between the fault node and the remaining nodes to ensure system stability in the event of a severe load imbalance in the event loss a generator occurring in the electric system. The effectiveness of the proposed load shedding program has been demonstrated by analyzing the simulation results of the IEEE 39 system, 10 generators. The results show that: the method of load shedding proposed to reduce the amount of load shedding, frequency recovery time, faster voltage, and better recovery voltage values than traditional methods and algorithm AHP.

\section{ACKNOWLEDGMENT}

This research was supported by Ho Chi Minh City University of Technology and Education, Ho Chi Minh City University of Technology and LacHong University DongNai province under a research.

\section{REFERENCES}

[1] Jianfeng, D., Z. Shuangxi, and L. Zongxiang, A New Risk Indices Based Under voltage load shedding scheme.pdf. Department ofElectrical Engineering, 2005.

[2] Hsu, C.T., M.S. Kang, and C.S. Chen, Design of adaptive load shedding by artificial neural networks. IEE Proceedings Generation, Transmission and Distribution, 2005. 152(3): p. 415.

[3] Sadati, N., T. Amraee, and A.M. Ranjbar, A global Particle Swarm-Based-Simulated Annealing Optimization technique for under-voltage load shedding problem. Applied Soft Computing, 2009. 9(2): p. 652-657.

[4] easyneuralnetwork.blogspot.com, Basic Neural Network: Algorithm and Example. 2015.

[5] statcompute.wordpress.com, Generalized Regression Neural Networks and the Implementation with Matlab.

[6] Conference, P.S.C., Proceedings of the Tenth Power Systems Computation Conference, PSCC, Graz, Austria, 19 - 24 August 1990. 1990: Butterworths.

[7] Hooshmand, R. and M. Moazzami, Optimal design of adaptive under frequency load shedding using artificial neural networks in isolated power system. International Journal of Electrical Power \& Energy Systems, 2012. 42(1): p. 220-228.

[8] Bevrani, H., G. Ledwich, and J.J. Ford. On the use of $d f / d t$ in power system emergency control. in 2009 IEEE/PES Power Systems Conference and Exposition. 2009.

[9] Shekari, T., F. Aminifar, and M. Sanaye-Pasand, An Analytical Adaptive Load Shedding Scheme Against Severe Combinational Disturbances. IEEE Transactions on Power Systems, 2016. 31(5): p. 4135-4143.

[10] 10. FRCC, FRCC System Disturbance and Underfrequency Load Shedding Event Report 2008.

[11] Nhan Mai Ngoc, "Master Thesis: Study of load shedding using neural network and AHP algorithm", Ho Chi Minh City of University of Technology and Education, VietNam, 2017. 